\title{
11. Conclusion and Outlook
}

This study examined the multifarious ways in which sexuality and migration constitute each other by analyzing biographical narratives of queer migrant women in Switzerland. Although recent shifts in Swiss immigration and asylum policies and practices have significantly facilitated entry for (certain) queer people, this 'group' of immigrants has received little political or academic attention to date. Instead, public discourses including political debates, media reports, and research largely continue to be organized around the assumption that female migrants are heterosexual. Hence, one chief concern of this research has been to complicate stereotypical images of migrant women by making visible the experiences, self-conceptualizations, practices, and positionalities of queer migrant women living in Switzerland.

In engaging with the subject position of queer migrant women, this study has drawn on and extended three bodies of scholarship. First, queer geographies, which examine the spatialities of sexualities and the sexualization of space. This body of work has only recently begun to adopt postcolonial perspectives and to address transnational configurations of desire. Second, queer migration studies, which have as yet produced few ethnographies addressing the subject position of queer migrant women, and which have rarely engaged with contexts outside of North America. Third, feminist migration research in Switzerland, which has lacked a queer perspective.

The study addressed queer women who have migrated to Switzerland and are perceived as racialized Ausländerinnen based on social markers such as language, surname, clothing, or skin color. 'Queer' was not how research participants identified themselves. Rather, the term was deployed as a conceptual umbrella that aimed to create space for the different conceptualizations of sexuality as represented by the 28 queer migrant women who took part in this study. The sample ultimately included participants who identified as lesbian, bisexual, and homosexual; one participant who identified as a pengkid (a sexual identity adopted by some masculine women in Malaysia); participants whose sexual identities did not align with their sexual practices (for instance because they identified as heterosexual but still engaged in same-sex relationships); and participants who understood their sexuality in terms of a practice rather than an identity.

Finding research participants and experts was challenging as this was a 'field without sites.' Since at the outset of this research in 2005 the Swiss organizational and insti- 
tutional landscape was organized either around sexuality or immigration, there was no 'natural' place from which to conduct the search. Eventually, participants were located through an eclectic multiplicity of channels, from web sites to immigration lawyers. With respect to expertise on queer migration to Switzerland, the knowledge excavated among LGBT and immigrant rights advocates, immigration authorities, and scholars was mostly restricted to queer male migrants (particularly asylum seekers).

Nevertheless, interviews were eventually conducted with 28 queer migrant women, originating from a total of 22 countries in Asia; Northern Africa; Latin America and the Caribbean; and in Eastern, Southeastern, and Southern Europe. This cultural diversity was both a strength and challenge in the research: On the one hand, it allowed for the tracing of issues, patterns, networks, and values across otherwise diverse accounts and positionalities; on the other hand, in-depth contextualizations of transnational and postcolonial configurations of desire (both in the home countries and in specific diasporas in Switzerland) were impossible to complete. The interviews with queer migrant women were complemented by reflexive photography, participant observation, and site visits and were contextualized by expert interviews with representatives from LGBT and immigrant organizations, immigration attorneys, and government officials. Most interviews were conducted between autumn 2005 and spring 2009, with some additional interviews conducted in autumn 2013.

Apart from making visible the presence, experiences, and needs of queer migrant women in Switzerland, the objective of this study was twofold. First, it was an attempt to gain a better understanding of transnational configurations of sexualities, as well as of the individual processes of identification with which these are intertwined. Selfconceptions and ideas about sexuality become contested in the diaspora, forcing queer migrants to navigate conflicting loyalties, diverging perspectives on sexualities, and multiple mechanisms of exclusion in the daily 'doing' of their identities. These processes of (dis)identification and the attendant efforts to create a sense of home and belonging were a chief focus of this study. A second objective of this study concerned the production and disruption of normative sexualities, seeking to address the question of how queer migrant women's self-conceptualizations and practices are shaped by, reiterate, or subvert dominant discourses around sexuality.

This concluding chapter summarizes the central insights gained from the analysis of the interviews conducted in this study and considers their broader implications.

\section{Transnational Trajectories of Desire}

Within the broader question of how migration shapes sexuality, a more specific point of interest has been how research participants perceive their sexualities and sexual identities to have changed through migration. This focus yielded rich insights into the complexity of transnational negotiations and configurations of sexualities, but also vehemently reinforced Michel Foucault's call to address sexuality as a "dense transfer point of power" (Foucault 1978:103).

The migrations of the interviewed queer women always entailed a shift in sexualities and/or sexual identities. These reconfigurations are characterized by two aspects in particular. The first is that all queer migrant women are forced to situate themselves 
in relation to the figure of the lesbian, even if they reject the lesbian label. Furthermore, these reconfigurations of sexualities entail a juxtaposition of pre-migration with postmigration conceptualizations of the sexual Self, which often involves a distancing from and/or denigration of pre-migration sexual identities and practices.

Three overlapping types of biographical trajectories were crystallized with regard to how sexualities shifted through migration. The first comprised the accounts of women who did not engage in relationships with women and/or did not consider their samesex practices in terms of an identity before migration, and who have come to explicitly identify as lesbians in Switzerland. This biographical trajectory is productive of narratives of self-discovery, liberation, and 'homecoming' to the lesbian identity. Moreover, these accounts framed the process of 'becoming a lesbian' as a crucial stepping stone to successful 'integration' into Swiss society. At the same time, it was shown that assuming a lesbian identity often entails denigration of one's sexual practices prior to migration. Since dominant discourses racialize non-Western queer sexualities as 'other,' queer migrant subjects often perceive their own queer pre-migration sexualities or other queer sexualities in their homeland as irreconcilable with the normative lesbian identity they now pursue.

The second biographical trajectory consisted of narratives by women who had already established a same-sex identity in their home country and were embedded in a sexual minority subculture prior to their migration. These participants attempted to gain access to the Swiss lesbian community after immigration, expecting the LGBT community to act as a gateway to their new social life. However, such integration efforts are impeded by experiences of rejection due to a culture of closure in the Swiss lesbian community, and sometimes by a sense of repulsion experienced due to cultural differences between the Swiss lesbian and the homeland queer subcultures.

The third biographical trajectory addressed the migration biographies of women who tended to understand their sexuality as a practice rather than an identity, and who continued to reject the lesbian label after migration. Defying Eurocentric valuations that equate silence/invisibility with being closeted, and being closeted with internalized homophobia, silence/invisibility is instead evaluated ambivalently. Frequently attributed to homeland culture, silence/invisibility is, on the one hand, seen as productive of a private sphere in which same-sex sexuality can be lived out without exposure to negative stereotyping. On the other hand, it is also seen as grounded in "tabooed taboos" around same-sex desire. For these interviewees, the proliferation of sexualized discourses and attendant stereotyping in Switzerland leads to a distinct sense of exposure of things they would rather keep private. Traces of this type of biographical trajectory were found in many accounts, especially in the context of some women's decision to keep tacit subjects tacit within their family as a sign of respect.

For the interviewed queer migrant women, both rejection and assumption of the lesbian identity hence remains partial, ambivalent, and contradictory. Rejection of the lesbian label necessarily remains contested because confrontation with sexual stereotypes persists in everyday life and because strategic identification is sometimes necessary to gain access to vital resources such as legal advice with regard to immigration or asylum procedure. Identification as a lesbian, although deployed as an 'integration' 
strategy, necessarily remains partial since the figure of the lesbian is inherently white, rendering the lesbian migrant woman an 'impossible subject.'

\section{Claiming Home}

A chief interest of this study has been to examine how queer migrant women create and reconfigure the space called 'home.' The absence of designated public or semi-public spaces for queer migrant women stands in contrast to their very presence. Consequently, queer migrant women are required to (re)negotiate and (re)appropriate real and imagined spaces and places in order to create a sense of belonging. The ambiguities that mark these processes of disidentification arise from queer migrant women's subject positions, which marginalize them on account of their gender, their national, ethnic, and cultural identity, and their sexual orientation (possibly among others). Seeking to draw an embodied geography, the focus of the analysis has been on how queer migrant women negotiate such conflicting loyalties in the everyday (and sometimes notso-everyday) 'doing' of their identities, and on how these identifications and practices both reiterate and disrupt dominant ideas about sexuality, gender, and 'culture.'

A range of everyday spaces and places emerged as crucial sites for queer migrant women's negotiations of home and belonging. These were the family of origin, the diasporic community, the queer community in the homeland, the Swiss lesbian community, the workplace, and the 'queer home.' Yet in each of these spaces belonging remains brittle, partial, and contested.

The family of origin as a site in which sexual, national, and cultural identities are negotiated was a key theme in many narratives. The interviewed queer migrant women were mostly - if not always - caught between love and affection for the family and a social and/or economic necessity to stay connected to their family on the one hand and the rejection they experienced due to their sexual orientation on the other. What could be perceived as a general phenomenon in many queer biographies is aggravated by migration: Social isolation, unemployment, racism, and other exclusions faced in the diaspora connect queer migrant women to their families in different ways than is the case for their 'Swiss' lesbian counterparts. For the interviewed women this meant that the family often represented a site of continuous negotiation or conflict across time and space.

These negotiations expose interviewees' families as central loci for the enforcement of heteronormative prescripts in the name of 'culture.' These notions of 'culture' are deeply gendered and sexualized and were shown to be co-shaped by the persisting coloniality of power, by heteropatriarchal nationalisms, and, in the case of diasporic communities, especially also by collective experiences of racism in the host society. ${ }^{1}$ Such culturalist discourses often epitomize (especially young) women as emblems of national culture, which subjects 'real' queer diasporic women to processes of disciplining. In many families this was especially also effectuated by silencing the queer family

Discourses on Western 'culture' are also gendered and sexualized and are equally shaped by the persisting coloniality of power and heteropatriarchal nationalisms (see Chapters 2 and 6.1.1). This is not discussed here as the issue here is research participants' role within the families in which they grew up. 
member's dissident sexuality. This ambivalent strategy defies easy alignment with the Western metaphor of the closet. On the one hand, silencing denied acknowledgment of what most interviewed women perceived to be an intrinsic part of their Selves, and many affected women accordingly suffered from this silence. On the other hand, as matters that are not verbalized but always understood, the narratives also confirmed that such "tacit subjects" (Decena 2012) also bind family members together in mutual respect. Due to this latter quality of silence (though mostly amalgamated with the fear of open rejection), queer family members are often complicit in keeping things tacit, especially if the family still lives in the country of origin. In this context migration emerges as a strategy to both explore one's sexuality and pay the family (and homeland 'culture') respect. Finally, in some contrasting cases families represented protected "queer islands in a heterosexual sea" (Siti Mohd Amin), enabling queer women to unfold their alternative sexualities. Women who grew up in such families frame these as exceptional within the societies of their homeland.

In conclusion, for the interviewed queer migrant women, the family as a 'basic unit' of solidarity and security in the diaspora, as the family has been described by feminist migration scholars (PASSAGEN 2014), is not available in the same way as it is to their heterosexual counterparts. Although none of the women were 'disowned' by their families (a fact which undermines popular discourses on exceedingly homophobic immigrant cultures' in Switzerland), as queer subjects their place in the family remained highly contested, restricting and complicating their access to this vital resource. At the same time, as the locus of the production and enforcement of 'culture' and 'tradition,' the family emerged as a crucial site of negotiation through which the interviewed women reclaimed their national and cultural identities as queer women.

Equally marked by ambivalence were the interviewed women's relationships to their diasporic communities. Four overlapping kinds of relationships to the diasporic communities were identified. The first was a fundamentally anti-identitarian stance characterized by resistance to be relegated to any minoritarian 'ghetto,' be it diasporic or lesbian. These interviewees consciously refrained from establishing their social contacts based on one or the other 'shared' identity. The second perspective on diasporic communities was marked by a sense of alienation and unbelonging in the face of dominant displays of heteronormativity in what was perceived as 'mainstream' diasporic spaces, which typically resulted in withdrawal from these very spaces. A third group of participants explicitly associated their diasporic communities with homophobia. This often led to a segregation of social worlds in which those 'in the know' (friends, lesbians) were separated from those 'not in the know' (diasporic community, often also family), and often equally entailed a withdrawal from diasporic circles. For the interviewed women, this sense of difference and unbelonging within the diasporic community caused disconnection from their national and cultural identity. One strategy with which this perceived lack was addressed was by seeking contact with queer compatriots and other culturally hybrid people, creating spaces in which national and cultural identities could be reconfigured as queer. Finally, the last - but in the analyzed sample exceptional - way of relating to diasporic communities was their framing as unproblematic sites of identification and attachment. The participants who took such a stance actively sought access 
to their diasporic community (with varying degrees of success). This perspective was mainly taken up by participants who did not identify as lesbian and/or did not understand their sexualities in terms of an identity.

In sum, the interviewed queer migrant women only had restricted access to the resources diasporic communities offer heterosexual migrants as a locus of homeland nostalgia and especially also as a bulwark against wider racism in the host society.

By contrast, for most interviewees the Swiss lesbian community represented a site of identification. As an imagined community, the lesbian community was sometimes - but by far not always - a 'pull-factor' in the decision to migrate. As an everyday space, although perceived by many as a 'ghetto,' it was often deemed the best of all wanting options considering the overall limited choice of spaces providing opportunities to socialize. Among the interviewed women, many felt that lesbian spaces were the spaces in which they could be "most the way I am."

However, this only concerned women who had assumed a lesbian identity and had succeeded in establishing social ties within the lesbian community. From the interviews it became very clear that for migrant women, access to the lesbian community is exceedingly hard-won. Experiences of exclusion in lesbian spaces dominate narratives about early stages of migration in particular, belying the myth of the universal inclusive 'queer family.' These exclusions are effectuated less by open racism than by a general culture of disinterest and closure. One participant's quip, "Lesbians in Bern? They are gorgeous, but they don't talk" (Charlotta Sembiring) encapsulates this experience. Experiences of exclusion in lesbian spaces could also become long-term if interviewees failed to assimilate to subcultural norms. This for instance happened when non-Western samesex identities were brought to lesbian spaces. Queer migrant women's narratives hence expose lesbian spaces as a site of production and enforcement of a normative - white, Western - homosexuality. Such closure kept many queer migrant women at a (both imposed and self-chosen) distance to Swiss lesbian circles. Lastly, participants who did not identify as lesbians and/or did not understand their sexual orientation to be formative of their identity did not seek membership in the lesbian community.

The workplace was a further crucial site of 'home-making.' In the context of migration, overcoming work-related obstacles and 'making it' in a foreign context is a major source of self-assurance. Conversely, work-related problems trigger existential fears, self-doubts, and health issues. In queer migrant women's narratives, the workplace accordingly emerged as a site of personal development and integration as much as a site of exclusion and personal crisis. Although work-related issues were rarely directly connected to issues related to sexuality, the two were intimately linked. Generally, the successful establishment of a 'good life' in Switzerland was considered to be contingent on both a fulfilling private and professional life. What may be seen as a general truth for all migrants is particularly momentous for queer migrant women. Early phases of migration in particular were often characterized by unemployment or deskilling, or by failure in forging social contacts at work. This sometimes coincided temporally with the process of realizing and acknowledging one's same-sex desires. In concert with the above-mentioned struggles faced in other areas of life, this often led to social isolation, 
severe personal crises, and health problems. Vice versa, participants who had 'made it' viewed the process of assuming a lesbian identity and establishing themselves professionally as intrinsically linked central stepping stones in establishing a 'good life' and achieving 'integration' in Switzerland.

Two other aspects distinguished queer migrant women's position with respect to work from that of their heterosexual counterparts. First, in the face of deskilling and unemployment, the alternative of becoming a housewife and mother is not available to queer migrant women in the same way as it is to heterosexual migrant women; where the latter win social recognition, the former tend to receive more rejection, at least at the outset of their 'baby projects.' Further, in addition to exclusions based on their status as perceived Ausländerinnen in Switzerland, queer migrant women must negotiate the persistent 'aggressive heterosexuality' of work environments in Switzerland, which creates its own exclusionary effects for migrants and non-migrants alike.

For the interviewed queer migrant women, a sense of home and belonging is hence hard-won. As landscapes of marginalization, their everyday lives and spaces are sites of negotiation, contestation, and exclusion. Restricted and complicated access to several resources that migration scholars have identified as vital to people in the diaspora renders queer migrant women's positionality within Swiss society more precarious than that of their heterosexual counterparts. The brittleness of this position results in numerous concerns and health problems, such as marked social isolation (which all participants who had traveled to Switzerland as adults were affected by at some point), deskilling, exploitative working conditions, unemployment, and bullying, factors which led many of the women interviewed to suffer from depression, stress, burnouts, or nervous breakdowns.

\section{Queer Homes}

Queer migrant women's struggles to create a sense of belonging testify to their 'homing desires, that is "desires to feel home as achieved by physically or symbolically (re)constituting spaces which provide some kind of ontological security in the context of migration" (Fortier 2003:115). These homing desires become particularly apparent in the conceptualization and actualization of what I called 'queer homes.' These are safe and harmonious spaces which reconcile aspects of the Self that in most other spaces are experienced as irreconcilable, and as such enable queer migrant women to be 'whole in one place.'

Such queer homes are, for instance, actualized in the women's private homes. Here, lesbian posters are placed side by side with an oversize flag of the homeland, materializing the possibility of being both a lesbian and a Bosnian, for example. As a space governed by one's own rules, the dwelling place also provides an arena for communication and - often silent - negotiation with family members: When the family visits, the lesbian posters stay on the wall, enabling the queer family member to silently confirm her sexual choices while showing respect for tacit subjects within the family. As such the queer home appears as a source of self-assurance and self-determination, assisting in the successful navigation of everyday struggles. 
A further central strategy in establishing a queer home is founding a queer family. The majority of the women interviewed were planning to have children. This was above all grounded in their desire to restore the family home of their youths, which as an everyday space had been lost to them on account of geographical distance and/or experiences of rejection by their families. Several interviewees related that their desire to establish their own family had been so dominant that at some point in their lives they had considered adopting a heterosexual lifestyle for the sake of installing a family. This particularly concerned women who originally could not imagine starting a family or marrying in the context of a same-sex couple because they saw it as operating "against the culture" (Siti Mohd Amin). Establishing a queer home through reproduction hence requires reconfigurations of cultural, sexual, and gender identities and attendant family roles.

A sense of home was also mapped onto the bodies of queer compatriots and other culturally hybrid people to address the desire to "sharing problem together" (Siti Mohd Amin). As in most cases queer compatriots could not be found in Switzerland, the desire to establish such ties were sometimes sought and actualized online. However, physical distance from the people behind these online communities eventually rendered membership in these homeland queer communities partial and unfulfilling. In the absence of queer compatriots, contact was also sought to other queer migrants, although these connections did not always bring the desired sense of connection.

Similarly, the few participants who were born in or had come to Switzerland early in their lives expressed a desire to connect to other culturally hybrid people (not necessarily queer, and not necessarily compatriots) in order to share the paradoxical sense of "being foreign in one's own homeland" (whereas "homeland" here refers to Switzerland). Furthermore, 'second generation' participants often sought to reclaim the parents' homeland by que(e)rying it. In contrast to many heterosexual 'second generation' migrants, the (few) 'second generation' participants in this study were not considering their parents' country of origin as a place to live, which was partly explained by fear of homophobia. Nevertheless, the parents' homeland remained an important surface of inscription for homing desires. Aspiring to act as co-authors (rather than only readers of) these places, the parents' homeland is reimagined and reclaimed by questioning the images conveyed in parents' heteronormative discourses, as well as by locating womenloving women in its territories. Contact is sought to queer women 'there,' aiming to reconfigure imaginations of the parental homeland, as well as to allow for the sharing of common experiences.

As the example of que(e)rying the parents' homeland shows, queer homes are sometimes carved out within spaces that are hegemonically inscribed as either lesbian or diasporic. In such moments of attachment, the hegemonic meanings attributed to these spaces become suspended. For instance, for Teresa Ruiz, moving to the music of her homeland with other lesbians in Switzerland transforms what was a lesbian space into a queer space, merging otherwise segregated aspects of her identity. Her corporeal presence and performance in this space momentarily diasporizes the otherwise intrinsically white lesbian space. 
As spaces in which queer migrant women can be both migrant and queer in one place, queer homes cancel the otherwise obsessive segregation of space into either migrant or lesbian. In these alternative spaces - which are sometimes fleeting and sometimes more permanent - hegemonic sexual and cultural norms are replaced by transnational configurations of queer desire. At the same time, even within these 'queer homes' the reconciliation of the irreconcilable remains partial and deferred; the family picture on the refrigerator, even if placed next to the self-portrait with the partner, marks both the family's presence and its absence.

In light of queer migrant women's narratives, the importance of queer homes can hardly be overestimated. Those research participants who had succeeded in creating such spaces identified this achievement as a crucial stepping stone in establishing a 'good life' in Switzerland. Conversely, having failed to do so was productive of a sense of unbelonging, isolation, lack, and deferral. The centrality of homing desires in the interviewed women's accounts fundamentally challenges Larry Knopp's and other queer geographers' localization of queer people's ontological and emotional security in movement, displacement, and placelessness, framing these states per se as a "queer practice" (Knopp 2004:124). As discussed at the outset of this study, Knopp explains this by reference to the keen awareness queer people have of the "hybrid nature of [their] existence," which leads to their "ambivalent relationship to place and identity" and their "affection for placelessness and movement" (ibid:129). By contrast, the biographical narratives of queer migrant women generated in this study testify to the central importance of location in the process of creating a sense of home. ${ }^{2}$ This insight challenges the presumption that moving queer bodies necessarily become detached from their moorings, or do not desire such moorings. At the same time, however, queer migrant women's queer homing practices fundamentally upset notions of 'home as origin' that continue to haunt much of mainstream migration scholarship.

\section{Controlling and Disciplining Queer Migrant Sexualities}

Queer migrant women's reinventions of their sexual Selves, their reconfigurations of their homelands, their everyday negotiations of multiple discrimination, and their actualizations of queer homes represent creative practices exposing and upsetting normative ideas about both 'our' (Western) and 'their' (non-Western) sexuality and culture. At the same time, these practices are closely tied to relations of power. From a critical queer postcolonial perspective, the process of 'becoming a lesbian' as narrated by queer migrant women emerges as a process of becoming a good lesbian, one who conforms to homonormative ideals prevailing in Switzerland that privilege specific ideas about and practices around gender, love, sexual practices, visibility, relationships, reproduction, community, citizenship, psychological configuration, clothing, housing, and so on. Becoming a 'good lesbian' is crucially enabled by private or institutional catalysts such as European partners or psychiatrists, who figure as teachers and facilitators of 'good lesbianism, even in the intimate sphere of the bedroom. 
The process of 'becoming a (good) lesbian' is not at all necessarily 'bad.' Women who came to identify as lesbians in Switzerland often described this process as one of personal learning, empowerment, and liberation. Assuming a lesbian identity also emerged as an effective strategy to 'integrate' into Swiss society: Because 'good lesbians' are assumed to be 'Swiss,' the performance of good lesbianism can (to a certain extent) 'save' one from being perceived as a 'foreigner.' In other words, from queer migrant women's perspectives, homonormativity can paradoxically also be reread as a strategy of resistance to mitigate exposure to racism and xenophobia in Switzerland.

However, since 'good lesbianism' is intrinsically marked as Western and white, integration necessarily remains partial and comes at a cost. As mentioned above, for queer migrant women becoming a 'good lesbian' often implies a devaluation of homeland cultures, sexualities, and experiences, which may lead to a sense of betrayal of, or disconnection from, one's national or cultural identity. This brings to the fore that queer migrant women's everyday negotiations of their sexual-cum-national identities with partners, friends, family, and so on are always also negotiations of their sexual citizenship. As such, these negotiations are shaped by discourses and practices of the state and other institutions and organizations that function as a carceral archipelago that disciplines, regulates, and controls migrant sexualities (Luibhéid 2002).

Tracing the effects of such regulatory discourses and practices, this study examined queer migrant women's experiences with legal frameworks that emerged as central to the disciplining of migrant sexualities in Switzerland. These frameworks define the formalization of same-sex partnerships and immigration/asylum procedure respectively. Interviewees' experiences with the same-sex Partnership Act were ambivalent. For many participants in this study, the Act had brought significant relief, had improved transnational mobility, and had even made dreams come true. At the same time, the Act continues to exclude many others, such as working class immigrants who cannot provide a "prétexte" (Nour Saber) like education or a job to enter the country; singles; or immigrants who do not happen to be in a relationship with a Swiss citizen or another legalized immigrant. However, even for interviewees who were eligible for registration, the Partnership Act by no means erased all concerns but instead raised new issues. Many research participants initially perceived that to 'marry' a woman would be to "go against our culture" (Siti Mohd Amin). Hence, to enable registration, a reconfiguration of homeland culture and a renegotiation of loyalties is required, but this was not always sought or achieved. Some participants had indeed refrained from registering for such cultural reasons, even in the face of legal precarity and threatening expulsion from the country. Consequently, in (the numerous) cases in which the right to stay in the country hinged on the implementation of same-sex partnership formalization, this process was tied to a distinct sense of coercion, which in some instances also threatened partnerships. Hence, in a paradoxical twist, the Partnership Act and attendant practices create the very realities they seek to discourage and penalize, such as unstable relationships or fictitious partnership registration. This mechanism becomes particularly evident in the dependency the Act forces upon the foreign partner, which creates inequalities within relationships.

These findings raise further questions from the point of view of Switzerland in its role as a receiving state and society. Interviewed immigration lawyers and activists sug- 
gest that a partial solution addressing these issues could be found in the reintroduction of 'hardship case' procedure (running parallel to the Act), which would enable the individual assessment of the immigration of the foreign partner independent of registration. This may foreclose rash or fictitious registrations and accommodate concerns regarding cultural loyalties. More radical solutions are being debated by queer scholars concerned with the fundamental rethinking of family relations, parenthood, and sexual citizenship in Switzerland. These models are guided by the principle that "a legal system in a pluralistic society that values all families should meld as closely as possible the purposes of law with the relationships that that law covers. Marriage is not the right dividing line" (Law Commission of Canada 2001, quoted in Mesquita and Nay 2013:210). In other words, these scholars suggest that law should serve relationships and realities, and not vice versa. In their efforts to embrace and serve plurality, however, queer scholarship in Switzerland should also reflect on its models with regard to transnational configurations of desire; to date, migrant experiences are largely absent from queer critiques of sexual citizenship, as is the question of who is absent from Switzerland in the first place.

Further, the practices by which the state disciplines migrant sexualities in asylum procedure were examined. It was demonstrated that in order to present a 'credible' case, queer asylum seekers are forced to reproduce a narrative of "Your country has failed you, you are safe here," hence becoming complicit in the perpetuation of the momentous dichotomy between an allegedly gay-friendly West and an allegedly homophobic South or Orient (Miller 2005). This entails the construction of a legible homosexual identity and biography that configures the asylum seeker as an individualized persecuted subject in her home country. As was shown in the example of Ramiza Salakhova, such an enforced 'coming out' can be exceedingly violent, harmful, and traumatizing.

In conclusion, I want to recall the disciplinary effect produced by the combined regulations of the Partnership Act and immigration/asylum procedure, which is that the state continues to discipline and control migrant sexualities after entry. This is not only directly effectuated (such as by 'imposing' partnership registration) but also, for example, by forcing immigrants and asylum seekers to live in rural areas remote from lesbian communities. Hence, queer migrants continue to carry a 'border within' ever after they have entered Switzerland.

\section{"It's always got to do with love": Sexuality as a Reason to Migrate}

Within the question of how sexuality shapes processes of migration, one of the interests here was the role sexuality plays in queer migrant women's decisions to migrate. At the outset of the biographical interviews I prompted research participants to tell me how they came to Switzerland. The beginning of their narratives would usually contain indications of why they had left their home countries, which were typically (analogously) "Because of work," "I came here to study," or "experience living abroad." However, as the narratives unfolded, these reasons to migrate moved to the background, yielding to a conglomerate of motivations based upon a broad range of experiences, desires, struggles, and curiosities. In virtually all cases, sexuality thereby emerged as a central motivating factor. Some had left their countries because they were heartbroken; some to join a partner in Switzerland; others because they experienced a vague sense of un- 
belonging and felt an urge to probe its causes (from a post-migration perspective, this sense of unbelonging was then often explained by the fact that one had 'always been' homosexual but had not been able to 'think' or 'see' it due to a lack of visible role models). One participant was sent abroad by her parents to separate her from her girlfriend; two left because they wanted to immerse themselves in the gay and lesbian subcultures of urban Western Europe; some sought to escape the pressure exerted by parents to marry and have children; two left explicitly because they felt discriminated against as homosexuals in their home country; and one couple fled their country to escape the domestic violence that one of the partners was subjected to after her husband had learnt about the women's relationship. In many cases, these motivations replaced the ones mentioned at the outset of the interviews. The latter were relegated to being 'pretexts,' while motivations related to sexuality were presented as the 'real' reasons that migration had been undertaken, which was expressed in statements like "This is actually why I left" or "This was the real reason why I left."

Hence, in the sample examined in this study, sexuality-related issues figure as a central driver for many (but not all) migrations. As one participant said, "Hat immer mit der Liebe zu tun" - "It's always got to do with love." However, for the women interviewed, sexuality was implicated in their motivation to migrate in different ways than proposed by some queer migration scholars. Particularly, the insights gained in this study with regard to research participants' motivations to migrate invigorate the debate around the notion of sexile, or sexual migration within queer migration studies. This concept emerged from work focusing on Latina/o migration to the U.S. and was defined by Manolo Guzmán as "the exile of those who have had to leave their nation of origin on account of their sexual orientation" (Guzmán 1997:227, quoted in Peña 2010:194). Other queer migration scholars have adopted this concept, sometimes interpreting it in narrow terms. ${ }^{3}$ As Andrew Gorman-Murray notes, "many [queer people] move simply for education and employment opportunities; this, in itself, I do not denote as queer migration" (Gorman-Murray 2009:443). In Murray's account, migration has to be directly and explicitly related to sexuality and sexual orientation in order to qualify as a queer migration. ${ }^{4}$

However: If Gorman-Murray's model holds true, what are we to do with one of his own informant's statements: "So I moved to the city in order to come out. Although I wouldn't have said it so succinctly then, I think that was the primary motivation" (GormanMurray 2009:448, emphasis added)? The insights gained in this study strongly suggest that meaningful theorizations of queer migration must be able to address such a lack of words. They must ask what ideas about sexuality emerge from these interstices, and what they entail for someone moving from one place to another. Moreover, singling out

3 But see e.g. Carrillo 2004, Howe et al. 2008, and La Fountain-Stokes 2008 for more encompassing conceptualizations of sexile and sexual migration.

4 Corman-Murray distinguishes three types of "queer migrations": 1) The coming-out migration (i.e. "moving for self-reinvention as a non-heterosexual"); 2) the gravitational group migration (i.e. "moving to be near a neighborhood with a gay and lesbian presence"); and 3) the relationship migration (i.e. "moving with a partner" or "away after relationship breakdown") (Gorman-Murray 2009:446). 
sexuality as an aspect of identity that can be analyzed in isolation - which is precisely what Gorman-Murray's definition of queer migration aims to do - fails to address that sexuality is always already intersectional, and that the motivations of queer people to migrate are complex and not always related to sexuality in easily discernible ways. Had my research participants been asked prior to being accepted into the sample whether they had migrated based on their sexual orientation, most would likely have answered in the negative. However, excluding these cases from the study would have robbed it of its most important insights about postcolonial and transnational configurations of desire and the motivations to migrate that these are productive of.

Furthermore, focusing investigations of queer migration on the reason to migrate does little to invite questions about the mutual constitution of sexuality and migration. For instance, such thinking does not encourage exploration of how 'integration' into the receiving society changes queer migrants' conceptualizations of their sexuality; nor does it easily incorporate questions of how queer migrants' sexualities inform ideas about sexuality prevailing in the receiving communities. Hence, in order to acknowledge the complexity of the ways in which sexuality and migration hang together, in contrast to Gorman-Murray I suggest including all queer people who migrate in analyses of "queer migration," regardless of whether they migrated explicitly based on their sexuality or not. In this view, 'queer migration' is simply the migration(s) undertaken by queer people; taking seriously queer theorists' insight that sexuality co-shapes all aspects of the social, these migrations are necessarily always also 'sexual' (and this is of course true for non-queer people as well).

\section{Switzerland: Promised Land for Queers from around the World?}

What 'love has to do with it' as emerged from queer migrant women's narratives in this study also contrasts with the ways in which dominant discourses in Switzerland and generally in Western European countries configure the queer migrant. "Immigration discourse," Lauren Berlant writes about the U.S. context, "is a central technology for the reproduction of patriotic nationalism: not just because the immigrant is seen as without a nation or resources and thus as deserving of pity or contempt, but because the immigrant is defined as someone who desires America" (Berlant 1997:195, emphasis original). As shown in the introductory chapters of this study, in Switzerland the notion of the immigrant desiring Switzerland and attendant fears of 'floodgate effects' have been excessively productive of restrictive immigration and asylum policies and practices.

This notion of the desiring immigrant is reiterated and exemplified in the figure of the queer immigrant. The dominant idea about queer migrants circulating in Western Europe is, in simplified terms, that they are oppressed in their homeland and desire a liberated homosexual life in the West, which they attempt to materialize by migrating to the West. In the interviewed women's narratives, this discourse emerged in contradictory versions. On the one hand, most accounts reiterated the imagination of a gayfriendly Switzerland. For some (few) women the image of the gay-friendly West was indeed an explicit motivation for migration, and generally most interviewees considered Switzerland to be a gay-friendly country (often: as opposed to their home countries). At the same time, this positive view of Switzerland was paralleled (frequently within the 
same narrative) by accounts of persistent, multiple, and severe experiences of exclusion, some of which were also explicitly associated with homophobia. In other words, while the imagination of 'Switzerland' as a gay-friendly space continued to prompt a sense of identification for queer migrant women, their actual experiences in its territories exposed the image of Switzerland as a promised land for queer migrants as a self-serving stance erasing persistent homophobia - as interlocked with racism and sexism - in Switzerland. In other words, to frame Switzerland as welcoming of queer migrants clearly ignores racism and xenophobia in the country. This in turn unmasks that gayfriendliness is only available to non-migrant homosexuals - and even in their case remains partial, as persisting discriminatory legislation, policies, and practices testify to.

Queer migrant women's migration biographies debunk the notion of the 'desiring' queer immigrant in two additional ways. The first concerns the reason to migrate. As discussed above, although sexuality is often centrally implicated in the departure from the home country, the notion of the migrant explicitly desiring Switzerland as a gayfriendly place gains some explanatory power in a small minority of cases only (and even then remains problematic as it fails to acknowledge non-Western configurations of desire). However, most narratives push the notion of the desiring queer immigrant beyond its limits. For instance, one cannot migrate explicitly on the basis of one's samesex desire if one cannot think or name this desire. This is an insight that, while simple, highlights blind spots in immigration, asylum, and 'integration' policies and procedures. For instance, the frequent inability of queer asylum seekers to 'name' their yet unnamed sexuality continues to insufficiently be taken into account in Swiss asylum procedure.

The second insight that challenges the figure of the queer immigrant desiring Switzerland is some interviewees' plans to return to the home country. Within the oppression-liberation narrative, the figure of the queer returnee inhabits a paradoxical space - why would someone want to return to oppression by her own volition? "I'm good here, but I'm better there," Charlotta Sembiring assessed, and a short while after the interviews she returned to her home country, as did at least one other research participant. ${ }^{5}$ The motivations for these return migrations specifically included a sustained lack of social embeddedness in Switzerland; a sense of cultural unbelonging; the presence of a partner in the home country; the lack of a partner in Switzerland; deskilling and unemployment; immigration issues; work load; exposure to racism, xenophobia, and discrimination; a longing for family; or the need to reassume one's role in the family of origin or more broadly in one's country.

\section{Towards a Progressive Politics: Some Thoughts for Human Rights Advocates}

The figure of the queer immigrant desiring Switzerland is also reproduced by LGBT rights discourses in Switzerland. As laid out in this study, queer migrants - and especially queer migrant women - have largely remained absent from public discourses in Switzerland. While LGBT organizations have mostly been complicit in this silence, some organizations have addressed the subject position of queer migrants, albeit mostly in

These returns took place after the field phase and are hence not documented systematically. Charlotta Sembiring re-returned to Europe later. 
the context of asylum claims and - before the Partnership Act came into effect - in the context of 'hardship cases.'

However, with a few notable exceptions ${ }^{6}$ the stories these organizations tell about queer migrants have largely remained stories about 'us' rather than 'them.' The identity politics they are based on largely frames immigrants as suppressed and closeted homosexual 'brothers and sisters' of an imagined universal queer family in need of being empowered to become 'out and proud' lesbians and gays. Through such discourses, LGBT rights advocates reproduce the world "in their own image," effectively creating the (universal LGBT) population they seek to protect and liberate (Massad 2009).

This narrative is problematic because it subsumes all people who are desirous of the same sex under the labels of 'lesbian,' 'gay,' or 'homosexual.' It erases - or dismisses as suppressed or not fully formed - alternative configurations of same-sex desire, which may not be organized around the narrative of the 'coming out." In the context of migration, this means that individual queer immigrants' sexual self-conceptions, practices, and experiences are eclipsed by the limelight that LGBT rights discourse directs at 'queer immigrants,' making them invisible in the very moment they should become visible. A further problem with the gay liberation narrative is that it reinforces homonationalist discourses by outsourcing homophobia to non-Western 'cultures.' This erases persistent homophobia within Switzerland and forecloses a political critique thereof. Such dichotomizations also serve homonationalist discourses because they sometimes deploy LGBT rights to vindicate a politics of disciplining and exclusion of undesired immigrants, as the discussed example of the podium discussions organized by NETWORK illustrates (Chapter 3.4.3).

In sum: There is no doubt a pressing need for revised asylum and immigration legislation and practice that addresses the problems of queer people who attempt to enter Switzerland. At the same time, as LGBT rights advocates, we should reflect on the effects of deploying "strategic shortcuts" (that is, relying on discourses that stereotype queer and other migrants) to create attention for our issues (Miller 2005). Such racialized images of queer immigrants created by human rights discourses is also the result of a fixation on asylum and immigration procedure. Among other things, this has led to an inadvertent preoccupation with male immigrants, as most 'problematic' asylum cases concern men. This focus on asylum and immigration procedure renders unaddressed the challenges female queer migrants face in their everyday lives in Switzerland, be it as asylum seekers or regular immigrants - such as how to learn the language, to find friends, to find a place to live, to find (satisfying) work, or how to negotiate sexuality with family members, and how, within all this, to negotiate the daily experiences of exclusion based on gender, sexuality, and the perceived status as racialized Ausländer or Ausländerinnen in Switzerland. In other words, the focus of LGBT rights discourses on

6 Exceptions especially include the emerging activism by (queer) people of color in Switzerland, which started to take shape only after the field phase of this project (2005-2013) (see Chapters 1 and 2). Having said that, the analysis presented here continues to characterize much of mainstream LCBT activism in Switzerland.

7 This is not to imply that these 'different' cultures are in any way 'local,' 'original,' or 'authentic,' as I hope to have demonstrated throughout this book. 
deficiencies in asylum and immigration procedure implicitly frames queer migrants as racialized 'problem cases' rather than as contributing and participating citizens with everyday lives and concerns.

At the same time, it is one of these classical immigration 'problems' that opens up an opportunity to forge a more progressive and differentiated queer politics that acknowledges sexuality as a social category that is always interlaced with other realms of the social. As noted above, the Partnership Act produces dependency on the part of the foreign partner, which may bring about precarious legal and personal situations, for instance in the case of domestic violence or separation. These are issues heterosexual migrants, and especially heterosexual migrant women, have long been struggling with. In terms of human rights activism, the Partnership Act hence opens up possibilities for new coalitions between organizations focusing on LGBT and immigrant rights. In Switzerland, these possibilities have not been seized upon to date, but they have been recognized and explored by some organizations in the U.S. As this book diagnoses for the Swiss NGO landscape, Karma R. Chávez (2010) assesses that in the U.S., immigrant and LGBT organizations have largely refrained from linking their issues. Chávez directs attention to alternative kinds of activisms as implemented in the collaboration of Wingspan, a Southern Arizona LGBT Community Center (which has since closed operation), with the Coalición de Derechos Humanos (CDH), a grassroots immigrant rights and advocacy organization. Identifying the need to fight anti-immigrant and anti-queer oppression in coalition, these two organizations worked together for years. As Chávez writes, "although each individual organization focuses primarily on its 'own' issue, the mission and constituency of the other group always remain present in the actions in which they each engage," and, when warranted, the organizations team up. Chávez argues that such activism creates what Aimee Carrillo Rowe has termed 'differential belongings,' that is "an alternative mode of cultural citizenship, which can challenge the national social imaginary that figures queers and migrants as threats to family values and the good citizen" (ibid:137, see also Carrillo Rowe 2005). It is only by these activists' and organizations' choice to belong to each other that they can demand that policy makers address the causes and effects of interlocking oppression, such as the fact that "the nationas-white is always constituted in and by the nation-as-heterosexual" (Chávez 2010:137). Chávez admits that "differential belonging is not a mainstream form of political action because it is located outside most people's affective aspirations and it is, in a word, hard. [...] To long to belong otherwise is dangerous, threatening, and strange." Yet she sees much potential in "bringing people to coalitional subjectivities, where they cannot help but see their oppression and privilege as inextricably bound to others" (ibid:151). ${ }^{8}$

By contrast, in Switzerland (womens') immigrant and LGBT causes have mainly been treated separately. As mentioned above, while LGBT organizations do sometimes power, and not some homogenized identity, is privileged in determining one's political comrades. I'm talking about a politics where the non-normative and marginal position of punks, bulldaggers, and welfare queens, for example, is the basis for progressive transformative coalition work" (Cohen 2005). 
engage with migration-related issues, put in relation to the scope of the Swiss LGBT organizational landscape, these efforts have remained the exception. Conversely, among the numerous immigrant organizations in Switzerland, I am aware of only very few that actively addresses same-sex sexuality. By contrast, from the political stance Chávez proposes, common political concerns (such as the issues that arise from linking the residence permit to partnership formalization or work contracts) could be addressed more forcefully, as such a politics would unmask the interlocking of different mechanisms of marginalization. For at least some of the queer migrant women interviewed for this study, such coalitional activities could create a political space that disrupts the divide they experience between their sexual and migrant identities, creating an environment in which the meeting-up of these two aspects of the Self no longer requires movement from one space into another.

\section{What Space Has Got to Do with It}

This brings us back to space. The present study has been inspired and guided by the work of scholars who have called for more embodied geographies that refuse to frame 'discourses,' 'structures,' or 'nation-states' as ubiquitous conglomerates that 'somehow,' on the 'large scale,' determine the world and how it works. Instead, these discourses, structures, and scales are understood to be contingent on their embodied performative (re)production; and these performances are always necessarily flawed, different, and unpredictable.

A 'structure' view on queer migrant women's subject position in Switzerland would necessarily have emphasized their absence, exclusion, and victimization. At the same time, it would have been equally problematic to frame queer migrant women as unruly protagonists in a "queerer than queer" theory (Oswin 2006:788), as this would have downplayed the disciplining power of sexual norms, the effects of having to navigate multiple landscapes of exclusion, and desires for 'normalcy' und inconspicuousness. By contrast, taking the perspective of an embodied geography allowed addressing both the fact that there is a lack of designated spaces for queer migrant women in Switzerland and how their corporeal presence and everyday (and not-so-everyday) practices as queer-and-migrant subjects at once re-enact and upset what is 'normal' in Switzerland.

The accounts discussed in this study further extend the discussion of how space and sexuality are co-constitutive of each other. The 'Same' and the 'Other' space only come into being through imprinting dichotomized sexualities onto the according landscapes and bodies: The dichotomies of the colony versus the colonizers' homeland; of the immigrant community versus the white mainstream society; of the 'foreign' versus one's 'own' 'culture'; and of the urban versus the rural all hinge on specific sexualizations of these spaces that work towards maintaining imperial and heteropatriarchal geometries of power.

\section{Research Outlook}

In Switzerland, queer migration is still a very open research field, which to date has scarcely brought forth a handful of degree papers, less than a handful of scholarly publications, a few investigative newspaper articles, some reports by LGBT organizations 
addressing the issue of queer asylum, and only marginal notes in broader queer scholarship. This lacuna of academic knowledge on queer migration is not restricted to a lack of investigation into queer migrants' experiences and practices but points to a broader gap in knowledge about the ways in which sexuality shapes all aspects of international migration, not just the migration of queers, and the ways in which migration shapes the ways in which we think about ('our' and 'their') sexualities and 'cultures.' My hope is for a proliferation of research illuminating this nexus from a variety of disciplines, including, for instance, social sciences, legal sciences, psychology, health sciences, and economic and political sciences.

This study represents but a point of departure, and the absences in the sample examined here are obvious indications of paths in future research. Above all, the scarcity of working class participants that could be included in this study raises a range of questions, such as whether unqualified women do not or cannot emigrate in the first place; whether their absence is simply a demonstration of the effectiveness of Swiss migration policies in keeping unqualified migrants from outside the EU from entering the country (thereby excluding all queer migrants who are not able to create a "pretext" of pursuing education or work in order to enable their entry into the country); whether unqualified queer women have immigrated using traffickers or fictitious marriages and were therefore reluctant to share their experiences and strategies (which is also pointed to by the absence of undocumented immigrants in this study); or whether they did not take part in the study due to language issues or alternative understandings of their sexualities. In future research on queer migration, an explicit focus on the ways in which class and immigration status structures sexualities and migrations is likely to yield results that differ substantially from the ones provided here.

Another issue that was not possible to address systematically in this study was the role childrearing plays in the configuration of queer migrants' self-conceptions, labor divisions within the family, or experiences in their children's educational institutions. Here follow-up interviews with the same or other participants after a decade of having children might yield interesting results. Further questions are raised by the relatively small number of participants from Ex-Yugoslavian countries. This was the case despite the fact that citizens from Ex-Yugoslavian states make up one of the most sizeable diasporas in the country, and despite explicit efforts to include representatives of these diasporas in later phases of the sampling process. Seeing the significance of this diaspora both in terms of size as well as in terms of the stereotypical images attached to Ex-Yugoslavian citizens by dominant discourses in Switzerland (among other things, prevalent homophobia), a project focusing specifically on these subject positions would seem justified.

Another scholarly engagement I consider urgent is a more systematic and comprehensive analysis of the constitution and development of the increasing homonationalist discourses in Switzerland, of the implications of these discourses in current debates around asylum and immigration policies and practices, and of their effects on the lives of both queer and non-queer migrants in Switzerland. In the context of migration, these discourses, which pit a gay-friendly Western Europe against a homophobic Orient or South, manifest in the deployment of LGBT rights discourses to vindicate a politics of exclusion of allegedly homophobic immigrants (Gunkel and Pitcher 2008, Harita- 
worn et al. 2007). As exposed by my conversations with representatives of certain LGBT organizations as well as by my participation at some of these organizations' events addressing issues of immigration, in Switzerland (as elsewhere), such discourses are sometimes also driven by LGBT rights organizations themselves (see also Purtschert and Mesquita 2016). Further material haphazardly gathered on the issue moreover indicates that homonationalist discourses are also reproduced by political discourses, in the media, in government discourses, in election campaigns, and in negotiations of immigration and asylum policies and practices, among others. In the current heated political climate with regard to asylum and migration issues and with regard to discourses around national security and terrorism, we need to gain a better understanding of the mechanisms of exclusion working towards increasing the rifts between 'us' and 'them.' The growing deployment of sexuality to secure cultural, economic, and political hegemony justifies this call for a systematic analysis of who produces what kind of homonationalist discourse in which context and to what end. An integral part of such an examination should not only be how such discourses affect the lives of queer migrants in Switzerland - a work this study has begun -, but also how these discourses become negotiated through and disrupted by queer migrants' presence, self-conceptualizations, and practices. It is the thinkings and doings of these 'impossible subjects' that most blatantly expose the incongruities of homonationalist narratives; revisiting them insistently promises a way to look at the world and how it works in different ways. 
